\title{
AGAMA HINDU BALI DALAM KONTESTASI BUDAYA
}

\author{
Ida Bagus Made Satya Wira Dananjaya \\ Fakultas Ilmu Sosial dan Ilmu Politik, Universitas Mahendradatta - Denpasar \\ e-mail :gus_danajaya@yahoo.com
}

\begin{abstract}
Abstrak - Tradisi yang telah berjalan begitu lama dan diakui kesakralannya, tradisi memberikan acuan kehidupan dengan ritme-ritme repetitif, keagungan terhadap keharmonisan sehingga menanggalkan konflik. Agama memberikan nilai-nilai suci pada tradisi sehingga mendapatkan penguatan dalam tataran mental menjadi ruang sosio-mitis. Sedangkan modernitas adalah gagasan baru yang diinjeksi yang merupakan implikasi dari melelehnya sekat negara. Modernitas membentangkan kesadaran manusia tentang waktu yang tidak lagi repetitif tetapi linear, tidak lagi sakral tetapi sekular dimana progresifitas dan alternatif-alternatif kreatif diciptakan. Tradisi dan Agama merupakan budaya mitis-ekspresif mendapat tantangan dari budaya global yang progresif-kreatif datang melalui pariwisata. Politik sinergitas telah dilakukan untuk visi positif bagi kehidupan masyarakat. Namun, ketiga anasir ini tidaklah dapat didamaikan begitu saja, kontestasi budaya menjadi suatu keniscayaan.
\end{abstract}

Kata Kunci: tradisi, agama hindu dan kontestasi budaya

\begin{abstract}
Traditions that have been going on for so long and acknowledged their sacredness, tradition provides a reference to life with repetitive rhythms, the majesty of harmony, thus abandoning conflict. Religion gives sacred values to the tradition so that it can gain reinforcement at the mental level into a socio-mythical space. Whereas modernity have injects for new ideas, which have an implication of the melting of the state barrier. Modernity unfolds human consciousness about time which is no longer repetitive but is linear, no longer sacred but secular where creative progress and alternatives are created. Tradition and Religion is a mythical-expressive culture that is challenged by progressive-creative global culture coming through tourism. The politics of synergy has been carried out for a positive vision for people's lives. However, these three factors cannot be reconciled just like that, cultural contestation becomes a necessity.
\end{abstract}

Keywords: tradition, hinduism and cultural contestation

\section{Pendahuluan}

Polemik antara tradisional dan modern tetap aktual diperbincangkan, terlebih bagi wilayah yang dikenal atau diidentikkan dengan nuansa tradisionl yang kental dan bersahabat. Bali yang merupakan tujuan wisata internasional, pertemuan atau gesekan dengan budaya global adalah suatu keniscayaan. Selain kedua ranah tersebut terdapat juga anasir ketiga yang turut serta membangun identitas Bali yaitu agama Hindu. Agama Hindu diyakini secara akademis maupun praktis mempengaruhi kehidupan masyarakat dan diyakini memiliki visi bagi kehidupan manusia ke arah yang lebih baik. Bagaimana ketiga anasir ini bertemu, bergesekan bahkan berkontestasi?

\section{Pembahasan}

\section{Konstelasi Politik: Bali Sebagai Ben-} teng Terbuka

Bali sejak jaman pra-sejarah bukanlah pulau yang tertutup dari pendatang. Vlekke $(2017)^{1}$ mencatat Bali telah menjadi daerah persinggahan dagang intenasional sejak Abad ke 2 dengan membawa serta berbagai kepentingan, salah satunya budaya pendatang. Masuknya rohaniawan sekaligus cendekiawan dari pulau Jawa membawa kebudayaan daerah asalnya

\footnotetext{
${ }^{1}$ Vlekke, Bernard H.M, 2007. Nusantara. Jakarta: KPG
} 
telah memperkaya kehidupan lokal. Mulai dari Markandeya, Mpu Kuturan, Sang Kulputih, mentransmisikantata kebiasaan baru yang disebut Agama Balimelalui gaya pendidikan non-formal, sistem politik, ekonomi dan keagamaan. Tidak lupa pengaruh kebudayaan Cina serta agama Budha yang terintregasi dengan baik di Bali melalui jalur ekonomi dan politik ikut memperkaya kebudayaan Bali.Setelah itu melalui Hegemoni Majapahit penduduk Bali diintegrasikan berbagai kebijakan dari Pusat yaitu Jawa (Majapahit), sehingga menurut Utama (2016:5) ${ }^{2}$ masyarakat Bali tersegmentasi menjadi dua, yaitu wilayah yang sepenuhnya dikuasi oleh Majapahit disebut Bali dataran, sedangkan wilayah yang tidak tersentuh secara penuh oleh kekuasaan Majapahit disebut Bali Aga. Perlawanan kecil berupa penolakan masuknya agama Bali yang diberikan oleh rohaniawan jawa dari penduduk Bali di daerah pegunungan menambah kekayaan lokal yang konon lebih otentik dan bersahaja dengan nama bali aga, sehingga terdapat politik identitas antara orang dalam (dataran) dan orang luar (Bali aga). Pada masyarakat Bali dataran hirarki politik mulai kentara, pola-pola senioritas yang dipertahankan oleh bali aga mulai digugat dan ditinggalkan, sistem kerajaan mensyaratkan Raja menjadi Dewa. Interaksi Bali dan Jawa semakin intensif, dimana sekat gegografis semakin menipis sehingga eksodus pendatang dari jawa ke Bali tidak dapat dielakkan.

Setelah akhir kejayaan Majapahit di Jawa Timur, datanglah rohaniawan Dang Hyang Dwijendra yang melengkapi kebudayaan Bali dengan karya serta gagasan monumental berupa paham monotheistik serta pelinggih Padmasana. Dengan demikian konstruksi agama Hindu tradisional di Bali tidaklah tunggal, namun diadaptasi kemudian direproduksi. Datangnya para kolonial Belanda dengan politik pecah belah, serta adanya administrasi publik yang desentralisasi, dilanjutkan dengan perjuangan pasca penundukan Belanda di Bali, dikenal istilah Baru yang disebut Nasionalisme serta afirmasi paham-paham kesatuan Negara Republik Indonesia. Telah banyak Ide-ide berbasis Hindu dan

\footnotetext{
${ }^{2}$ Utama, Budi. 2016. Pudarnya Identitas Balgi Aga. Denpasar: UNHI.
}

Budhayang diambil untuk menjadi sumbangsih dalam pembangunan ideologi, insfrastruktur, sosial, dan budaya nasional. Bali secara geografis telah menjadi bagian dari Indonesia serta salah satu penyumbang karakteristik penduduk Indonesia yang dikenal anggun, ramah, toleran dengan keberagaman, dan memiliki jiwa seni dan estetika yang tinggi. Bali bersamaan dengan itu agama dan Kebudayaan Hindu telah terintegrasi kedalam Negara Republik Indonesia dengan konsekuensi sistem politik Bali tidaklah sepenuhnya otonom. Sistem regulasi dan legislasi Negara harus diikuti oleh Bali, pemegang otoritas Bali tidak dapat semena-mena menentukan nasib rakyatnya, walaupun ada hal-hal yang dapat diatur secara lokal namun Bali tidak lagi independen atau berdaulat. Hal tersebut terbukti masyarakat Bali harus berjuang keras lebih dari lima tahun untuk melegalkan agama Hindu sebagai agama resmi Negara.

Masuknya Bali dalam bingkai Negara Indonesia tidak serta merta menjadi akhir dari sejarah agama Hindu Bali, namun bertautan dengan integrasi Indonesia kedalam kancah perekonomian global yang tidak dapat dihindari memberikan dampak perubahan signifikan bagi kehidupan masyarakat Bali disemua lini. Sekat-sekat geografis kini tidak lagi menipis namun sepenuhnya telah putus anatar-negara. Tidak salah Nordholt (2007) ${ }^{3}$ menyatakan Bali sebagai benteng terbuka, Ide-ide global telah mengganggu kedudukan status quo tradisi, yang selama ini masih dapat bertahan dalam gugatan $\mathrm{Ne}-$ gara yang cenderung melakukan afirmasi terhadap nilai-nilai tradisional. Teknologi informasi yang menjadi jargon utama globalisasi memberikan kemampuan mobilitas yang begitu mencengangkan, sehingga ide-ide global baik itu ekonomi kapitalis, gaya hidup sosialita, sekulerisasi, individualistik telah menjadi pilihan baru bagi masyarakat Bali. Kini dunia telah dilipat, integrasi masyarakat Bali menjadi Masyarakat Global dengan pusat orientasi mengarah ke Pasar global membawa dampak pada hal yang paling sensitif bagi masyarakat yaitu agama. Pelaksanaan ag-

\footnotetext{
${ }^{3}$ Nordholdt, Henk, Schulte. 2007. Bali Benteng Terbuka 1995-2005. Denpasar: Pustaka Larasan.
} 
ama Hindu di Bali harus dimodifikasi agar tidak ikut terseret atau diganti arus jaman yang cenderung mengarah ke sekulerisasi. Produk-produk agama mulai dipertanyakan, mitos, ritual, mistisme, serta Tuhan mulai mendapat gugatan serius dengan vitalitas yang sebanding yaitu rasionalitas.

\section{Pariwisata Budaya: Sebuah Kontestasi Budaya}

Dalam konteks Bali abad 21 dengan jargon pariwisata Budaya yang dijiwai oleh Hinduisme memberikan sebuah gambaran bahwa adaptasi budaya global harus sesuai dengan budaya Bali dan ajaran-ajaran dalam agama Hindu. Pariwisata yang tentunya berbasis internasional karena sasaran tembak wisatawan Bali adalah turis asing, yang secara normatif harus dibentengi oleh budaya lokal dan ajaran agama Hindu, maka muncullah perda-perda ditingkat daerah serta awig-awig ditingkat Desa yang mengatur berbagai hal mengenai perubahan signifikan jaman melalui produk-produk budaya global. Berkenaan dengan itu kontestasi budaya kian sengit manakala antara budaya global, budaya Bali klasik, dan agama Hindu bertarung untuk menunjukan diri sebagai yang terdepan dalam menjaga pulau Bali dari kehancuran permanen akibat perubahan jaman. Kompetisi budaya di Bali kini melahirkan promosi budaya, dimana pariwisata menawarkan kesejahteraan peradaban tinggi berupa ekonomi yang lebih baik, kehidupan sekuler tanpa terikat oleh moralitas religius, profesionalisme, wisata belanja, teknologi canggih dan hiburan, sebuah kehidupan yang dianggap normal dan beradab. Sedangkan Budaya Bali mengingatkan kembali pada memori kolektif dimana Bali yang Asri dengan pantai yang tanpa Villanisasi dan Hotelisasi, Bali dengan masyarakat yang gotong royong dan akrab dengan Tanahnya, serta penghormatan terhadap leluhur. Mengacu pada Giddens $(2003: 27)^{4}$ masyarakat Bali tengah melakukan monitoring tindakan reflektif untuk meletakan kedudukan agama Hindu, tradisi dan budaya global dalam sebuah kontestasi budaya dalam praksis kehidupan. Posisi agama Hindu yang paling ter-

${ }^{4}$ Giddens, Anthony. 2003. Konsekuensi-konsekuensi Modernitas. Yogyakarta: Kreasi Wacana. jepit, dimana tradisi sering kali mencatut bahkan meminjam gagasan Hindu yang dirasa selaras dan serasi untuk memelihara keseimbangan, dilain pihak perubahan jaman yang tidak terelakan membawa agama Hindu kepada perubahan yang sesuai dengan konteks jaman agar tidak tergerus sekulerisasi. Revitalisasi ajaran agama Hindu terikat pada keterikatan terhadap konteks jaman, karena keusangan sebuah kebenaran tergantung pada penguasa pada masa itu dan pengetahuan yang diamini oleh penguasa.

\section{Munculnya Anomali: Signifikansi Strategi Kebudayaan}

Agama Hindu memiliki andil besar dalam pembentukan identitas dan kebudayaan Bali, pariwisata Bali sangat tergantung pada bertahannya tradisi dan budaya Bali sebagai daya jual tinggi, namun pergeseran jaman yang frontal yang tidak dapat dinafikan membawa dampak pada anomali. Pilliang (2013) $)^{5}$ mengartikan anomali sebagai keadaan yang membingungkan dimana budaya global membawa dampak perubahan signifikan bagi masyarakat lokal ke arah rasionalisasi dengan meninggalkan tradisi dan agama yang dianggap kuno dan usang menghambat proses industrialisasi untuk globalisasi, ekonomi kapital, mendapatkan jalan yang mulus sehingga akan timbul sekulerisasi. Masyarakat Bali sendiri dalam keadaan kebingungan, gebyar perayaan kebudayaan global dengan timbulnya gejala-gejala baru dalam masyarakat seperti individualistik, konsumsi produk-produk berkualitas dari luar negeri, konsumsi citra diri dalam pembentukan identitas kelompok, pelampiasan hasrat seksual, dan menjamurnya hiburan termasuk Hiburan malam yang merubah tatanan sosial dan psikologi masyarakat Bali mampu menyilaukan masyarakat.

Praktik-praktik tradisional seperti ritual yang dijaga ketat oleh kaum tua tradisional mendapat tantangan dari kaum muda modern untuk merasionalisasi ritual yang dianggap tidak efektif bahkan tidak signifikan. Paket-paket upacara adat dan agama yang bernuansa kapital, pemangkasan sistem gotong royong,

${ }^{5}$ Pilliang, Yasraf, Amir. 2013. Melipat Kebudayaan. Jakarta: Matahari. 
komodifikasi dan kapitalisasi unsur-unsur vital agama Hindu seperti air, tanah, sawah bahkan upakara serta tempat suci membuat sekat antara sakral dan profan menjadi kabur. Generasi dewasa ini tidak lagi dapat melihat jarak yang tegas antara yang disucikan dan yang boleh diperjual-belikan atau dipertontonkan,Upacara dan upakara dan tempat suci konon harus terbebas dari ego pribadi serta kerakusan namun segala bentuk komodifikasi dan kapitalisasi menandakan hal yang paling sakral dapat dinegosiasikan untuk mendapat keuntungan bagi pemilik modal. Pasar telah menentukan segala sesuatu yang dianggap berharga adalah baik dan sesuatu yang tidak menelorkan keuntungan dapat ditanggalkan bahkan ditinggalkan. Tercerabutnya masyarakat Bali dari akar tradisinya membawa dampak harus ada nilai serta norma baru yang menggantinya yang sesuai dengan atau paling tidak karakteristik identik kulturnya agar masyarakat tidak merasa terasing dari tanah kelahirannya.

Modernisasi memang tidak dapat dikatakan menghilangkan tradisi, modernisasi dapat berjalan dengan baik melalui interaksi dan negosiasi, namun tatanan moril tradisi harus mengikuti tatanan kehidupan modern. Tradisi ekspresif dapat saja berubah bahkan dihilangkan, tidak demikian dengan tatanan moril dari tradisi yang juga diafirmasi oleh ajaran agama Hindu, dimana mengutamakan kebersamaan, gotong royong, sikap ramah, saling peduli satu sama lain, penghormatan terhadap orang tua dan leluhur adalah bentuk sosial kapital yang tidak boleh bergeser dari hiruk pikuk kehidupan modern. Berkenaan dengan fenomena modernitas perlunya sebuah kebijakan dan strategi budaya bagi masyarakat Bali dengan terlebih dahulu memahami kebudayaannya sendiri dan melakukan suatu pemetaan menentukan kemana arah kebudayaan Masyarakat Bali ke depan.

\section{DAFTAR PUSTAKA}

Giddens, Anthony. 2003. Konsekuensi-Konsekuensi Modernitas. Yogyakarta: Kreasi Wacana.

Nordholt, Henk Schulte. 2007. Bali Benteng Terbuka1995-2005. Denpasar: Pustaka Larasan

Pilliang, Yasraf Amir. 2013. Melipat Kebudayaan. Jakarta: Matahari.

Utama, Budi. 2016. Pudarnya Identitas Bali Aga. Denpasar: UNHI

Vlekke, Bernard H.M, 2017. Nusantara. Jakarta: KPG 